\title{
Respon Pertumbuhan, Produksi dan Kualitas Daun Duduk (Desmodium triquetrum (L.) D.C.) terhadap Ketinggian Tempat Budidaya
}

\author{
(Response of Growth, Production and Quality of Daun Duduk (Desmodium triquetrum (L.) D.C.) to \\ Altitude of Cultivated Location)
}

Penulis

Afiliasi
Fauzi* dan Dyah Subositi

Balai Besar Penelitian dan Pengembangan Tanaman Obat dan Obat Tradisional, Badan Litbang Kesehatan, Kementerian Kesehatan RI. JI Raya Lawu No. 11 Tawangmangu, Karanganyar, Jawa Tengah, Indonesia 57792

\section{Kata Kunci \\ $\rightarrow$ Budidaya \\ $\rightarrow$ Desmodium \\ $\vartheta$ Kualitas \\ ? Tanaman obat \\ Keywords \\ $\rightarrow$ Cultivation \\ $\rightarrow$ Desmodium \\ $\rightarrow$ Quality \\ - Medicinal plant}

Diterima 12 Januari 2019

Direvisi 5 Mei 2019

Disetujui 20 Mei 2019

*Penulis Koresponding Fauzi email: fauzi.b2p2to2t@gmail.com

\section{ABSTRAK}

Daun duduk (Desmodium triquetrum (L.) DC.) merupakan tumbuhan obat yang mengandung senyawa flavonoid, saponin, polifenol dan trigonelin. Tanaman ini di Indonesia tersebar di pulau Jawa, Madura dan Sumatera. Tumbuh dari daerah dataran rendah sampai dataran tinggi pada ketinggian 5 - $1.500 \mathrm{~m} \mathrm{dpl,} \mathrm{sampai} \mathrm{saat} \mathrm{ini} \mathrm{belum} \mathrm{banyak} \mathrm{dibudidayakan.} \mathrm{Penelitian} \mathrm{ini} \mathrm{bertujuan}$ untuk mengetahui ketinggian tempat tumbuh yang optimal bagi pertumbuhan, produksi dan kualitas daun duduk. Penelitian dilaksanakan di kebun percobaan Balai Besar Penelitian dan Pengembangan Tanaman Obat dan Obat Tradisional pada bulan Januari - September 2016. Percobaan menggunakan Rancangan Acak Kelompok, faktor perlakuan yang dicobakan adalah ketinggian lokasi penanaman yaitu 200, 450 dan 1.200 m dpl. Hasil penelitian menunjukkan bahwa ketinggian tempat berpengaruh nyata terhadap pertumbuhan, produksi dan kadar flavonoid daun duduk. Tinggi tanaman tertinggi $(179,90 \mathrm{~cm})$ diperoleh pada penanaman di ketinggian $1.200 \mathrm{~m}$ dpl. Jumlah dan bobot kering daun tertinggi dihasilkan pada penanaman di ketinggian 200 m dpl. Kadar sari larut air (19,73\%), kadar sari larut etanol (18,28 \%), dan kadar flavonoid $(0,249 \%)$ yang tertinggi diperoleh di ketinggian $450 \mathrm{~m}$ dpl.

\section{ABSTRACT}

Daun duduk (Desmodium triquetrum (L.) DC.) is a medicinal plant containing flavonoid compounds, saponins, polyphenols, and trigonelline. These plants are spread throughout Indonesia especially on Java, Madura, and Sumatera. Growing from lowland areas to highlands at an altitude of 5-1,500 $\mathrm{m}$ above sea level, until now it has not been widely cultivated. The aim of this study was to determine effects of altitudes to growth, productivity, and quality of daun duduk. The research was carried out in the experimental garden of Medicinal Plant and Traditional Medicine Research and Development Center in January - September 2016. The experiment used a Randomized Block Design in four locations that has different altitudes such as 200, 450 and 1,200 $\mathrm{m}$ asl. The results showed that the altitude of location significantly affected the growth, production, and flavonoid contents of daun duduk. The optimal plant height (179.90 $\mathrm{cm})$ was obtained from altitude of 1,200 $\mathrm{m}$ above sea level. The highest number and dry weight of leaves were produced in altitude of $200 \mathrm{~m}$ asl. While the levels of water soluble extract was $19.73 \%$, ethanol soluble extract was $18.28 \%$, and total flavonoid content was $0.249 \%$ were obtained at $450 \mathrm{~m}$ asl. 


\section{PENDAHULUAN}

Daun duduk (Desmodium triquetrum (L.) DC.) merupakan tumbuhan obat yang tersebar luas di seluruh Asia Selatan, Asia Timur, dan Asia Tenggara (Vedpal et al. 2016). Daerah persebaran daun duduk di Indonesia meliputi pulau Jawa, Madura dan Sumatera yang digunakan masyarakat sebagai pelancar air seni, mengatasi wasir dan radang (Sa'roni et al. 2006). Pemanfaatan daun duduk secara tradisional di Cina untuk mengobati kencing manis, obesitas, demam, flu, sakit tenggorokan, hepatitis kolestatik, disentri, dan mual saat hamil (Zhang et al. 2016). Kandungan senyawa daun duduk antara lain saponin, flavonoid, polifenol, tanin, hipofarin, trigonelin, bahan penyamak, dan asam silikat (Haryanto 2009).

Daun duduk dikenal dengan nama daerah berbedabeda, di Sumatera disebut daun duduk sedangkan di Jawa memiliki banyak nama antara lain genteng cangkang, ki congcorang, potong kujang, cencen, daun duduk, gerji, dan gulu walang. Daun duduk termasuk dalam famili Fabaceae, berperawakan semak-perdu kecil, tumbuh tegak, bercabang banyak, berdaun tunggal dengan tangkai daun bersayap, helaian daun berbentuk lanset-bulat telur, pangkal membulat dan ujung meruncip-runcing, perbungaan majemuk, bunga kupu-kupu berwarna ungu kemerahan,buah berupa polong (Susilo et al. 1989, Syamsuhidayat dan Hutapea 1991).

Daun duduk dapat tumbuh dari daerah dataran rendah sampai dataran tinggi pada ketinggian 5 - 1500 $\mathrm{m}$ dpl. Hingga saat ini ketinggian tempat tumbuh optimal tanaman ini belum diketahui. Menurut Towaha et al. (2014) ketinggian tempat tumbuh sangat berpengaruh pada tanaman dan perlu mendapat perhatian utama karena sulit untuk dimodifikasi. Ketinggian tempat berpengaruh terhadap suhu udara, sinar matahari, kelembaban udara dan angin. Semakin tinggi suatu tempat, semakin rendah suhu tempat tersebut dan intensitas cahaya matahari semakin berkurang. Faktor suhu dan intensitas cahaya digunakan dalam penggolongan tanaman yaitu tanaman dataran rendah dan tanaman dataran tinggi. Hasil penelitian Zhang et al. (2016) menunjukkan bahwa faktor geografis atau lokasi tumbuh dan waktu panen dapat menyebabkan perbedaan profil fitokimia berdasarkan pola kromatogram UPLC (Ultra Performance Liquid Chromatography) pada daun duduk.
Penelitian budidaya daun duduk khususnya mengenai ketinggian tempat belum banyak dilakukan. Penelitian pengaruh ketinggian tempat tumbuh daun duduk terhadap pertumbuhan, produksi dan kualitas hasil dilakukan untuk mengetahui tempat tumbuh yang optimal.

\section{METODE}

Penelitian dilakukan di kebun percobaan Balai Besar Penelitian dan Pengembangan Tanaman Obat dan Obat Tradisional (B2P2TOOT), Kabupaten Karanganyar, Jawa Tengah pada bulan Januari - September 2016. Percobaan menggunakan Rancangan Acak Kelompok, perlakuan yang dicobakan adalah ketinggian tempat penanaman yaitu; Desa Tanjungsari, Kecamatan Karanganyar (200 m dpl), Desa Tohkuning, Kecamatan Karangpandan (450 m dpl), dan Kelurahan Kalisoro, Kecamatan Tawangmangu (1.200 m dpl).

Persiapan lahan tempat penanaman dilakukan dengan cara membersikan lahan dari gulma, mencagkul sedalam $30 \mathrm{~cm}$ dan membuat petak tempat penanaman dengan ukuran $2 \mathrm{~m} \times 2 \mathrm{~m}$. Sekeliling lahan dibuat saluran drainase untuk menghindari genangan air.

Bibit daun duduk yang digunakan berumur 2 bulan yang ditanam dengan jarak $50 \mathrm{~cm} \times 50 \mathrm{~cm}$, setiap petak berjumlah 9 bibit tanaman. Bibit ditanam dengan cara dikeluarkan dari polibag lalu ditanam pada lubang tanam yang sudah diberi pupuk kandang domba sebanyak $2 \mathrm{~kg} / \mathrm{lubang}$ tanam.

Pemeliharaan tanaman meliputi penyiraman, penyulaman dan penyiangan. Penyiraman dilakukan setiap pagi hari atau sesuai kondisi di lahan untuk menjaga ketersediaan air bagi tanaman. Penyulaman dilakukan 3 hari setelah tanam, dengan cara mengganti tanaman bila ada yang mati. Penyiangan dilakukan secara manual dengan membuang gulma yang tumbuh disekitar tanaman. Panen dilakukan saat tanaman berumur 120 hari setelah tanam (HST) dengan cara memotong tanaman $10 \mathrm{~cm}$ di atas permukaan tanah kemudian daun dipisahkan dari batang. Penanganan pasca panen meliputi sortasi, penyucian, penirisan dan pengeringan dengan menggunakan oven pada suhu $45^{\circ} \mathrm{C}$.

Variabel pertumbuhan yang diamati adalah tinggi tanaman dan diameter batang. Data produksi meliputi jumlah dan bobot kering daun, sedangkan data kualitas yang diamati antara lain kadar sari larut air, kadar sari larut etanol dan kadar flavonoid. 
Analisis data menggunakan analisis sidik ragam pada taraf $5 \%$ dan bila terdapat pengaruh yang berbeda nyata maka dilanjutkan uji jarak berganda Duncan pada taraf $5 \%$ untuk mengetahui perbedaan antar taraftaraf faktor perlakuan.

\section{HASIL DAN PEMBAHASAN}

Tinggi Tanaman dan Diameter Batang .

Hasil analisis ragam menunjukan bahwa ketinggian lokasi penanaman berpengaruh nyata terhadap pertumbuhan tinggi dan diameter batang tanaman pada umur 60, 90 dan 120 HST. Analisis lanjut menunjukan penanaman pada ketinggian $1.200 \mathrm{~m}$ dpl menghasilkan tinggi tanaman yang lebih tinggi pada umur 60 HST, 90 HST dan 120 HST dibandingkan dengan lokasi penanaman $200 \mathrm{~m} \mathrm{dpl}$ dan $450 \mathrm{~m} \mathrm{dpl}$ (Tabel 1.). Diameter batang pada penanaman di ketinggian $1.200 \mathrm{~m}$ dpl lebih kecil dan berbeda nyata pada umur 60 HST (Tabel 2.). Ketinggian tempat terhadap tanaman berkaitan erat dengan faktor lingkungan, pada penelitian ini tidak melakukan pengamatan lingkungan. Beusekom et al. (2013) dalam Supriadi et al. (2015) menyatakan bahwa semakin tinggi tempat, suhu udara semakin rendah dan curah hujan semakin tinggi serta tanahnya semakin subur. Intensitas cahaya dipengaruhi oleh keadaan atmosfer sebagai media yang dilewati cahaya seperti awan dan uap air. Daerah sering berawan maka intensitas cahaya akan rendah karena banyaknya cahaya yang direfleksikan oleh awan (Budiastuti 2010). Intensitas cahaya rendah menyebabkan pertumbuhan panjang batang lebih terpacu sehingga tanaman lebih tinggi, namun tanaman menjadi lemah dan batang tidak kokoh (Pantilu et al. 2012, Buntoro et al. 2014, Dechairani et al. 2014)

Respon pertumbuhan tinggi dan diameter batang tanaman terhadap ketinggian tempat tumbuh tergantung pada jenis tanaman.. Tanaman Edamame yang ditanam pada dataran tinggi menghasilkan pertumbuhan tinggi tanaman lebih tinggi dibandingkan yang ditanam pada dataran rendah (Hakim 2012). Penelitian Nurnasari dan Djumali (2010) terhadap tanaman tembakau yang ditanam pada ketinggian 880 m dpl, 1245 m dpl dan 1395 m dpl menunjukan hasil bahwa semakin tinggi tempat penanaman, tinggi tanaman semakin menurun. Penanaman cabai katokkon (Capsicum chinense Jacq.) pada ketinggian tempat $600 \mathrm{~m}$ dpl dan $1200 \mathrm{~m}$ dpl menghasilkan tinggi dan diameter batang tidak berbeda nyata (Flowrenzhy dan Harijati 2017).

\section{Jumlah dan Bobot Kering Daun}

Jumlah daun dan bobot kering daun tertinggi dihasilkan pada perlakuan penanaman di ketinggian $200 \mathrm{~m}$ dpl serta menunjukan perbedaan nyata dengan penanaman di ketinggian $450 \mathrm{~m}$ dpl dan $1.200 \mathrm{~m}$ dpl. Jumlah dan bobot kering daun terendah diperoleh pada penanaman di ketinggian $1200 \mathrm{~m} \mathrm{dpl}$ (Tabel 3).

Tabel 1. Pengaruh Ketinggian Tempat Penanaman terhadap Tinggi Tanaman pada Umur 30, 60, 90 dan 120 HST

\begin{tabular}{ccccc}
\hline \multirow{2}{*}{ Lokasi Penanaman } & \multicolumn{4}{c}{ TinggitTanaman (cm) } \\
\cline { 2 - 5 } & $\mathbf{3 0 ~ H S T}$ & $\mathbf{6 0}$ HST & $\mathbf{9 0 ~ H S T}$ & $\mathbf{1 2 0}$ HST \\
\hline 200 m dpl (Karanganyar) & $33,94 \mathrm{a}$ & $42,28 \mathrm{a}$ & $80,35 \mathrm{a}$ & $163,30 \mathrm{a}$ \\
450 m dpl (Karangpandan) & $27,39 \mathrm{a}$ & $44,40 \mathrm{a}$ & $82,28 \mathrm{a}$ & $170,69 \mathrm{ab}$ \\
1.200 m dpl (Kalisoro) & $30,53 \mathrm{a}$ & $55,26 \mathrm{~b}$ & $90,24 \mathrm{~b}$ & $179,90 \mathrm{~b}$
\end{tabular}

Keterangan: Nilai rata-rata yang diikuti huruf yang sama pada kolom yang sama menunjukkan tidak berbeda nyata menurut Uji Jarak Berganda Duncan pada taraf $5 \%$.

Tabel 2. Pengaruh Ketinggian Tempat Penanaman terhadap Diameter Batang pada Umur 30 dan 60 HST

\begin{tabular}{ccc}
\hline \multirow{2}{*}{ Lokasi Penanaman } & \multicolumn{2}{c}{ Diameter Batang (cm) } \\
\cline { 2 - 3 } $200 \mathrm{~m} \mathrm{dpl}$ (Karanganyar) & $\mathbf{3 0 ~ H S T}$ & $\mathbf{6 0 ~ H S T}$ \\
$450 \mathrm{~m} \mathrm{dpl}$ (Karangpandan) & $0,30 \mathrm{a}$ & $0.60 \mathrm{~b}$ \\
$1.200 \mathrm{~m}$ dpl (Kalisoro) & $0,30 \mathrm{a}$ & $0,59 \mathrm{~b}$ \\
\hline
\end{tabular}

Keterangan: Nilai rata-rata yang diikuti huruf yang sama pada kolom yang sama menunjukkan tidak berbeda nyata menurut Uji Jarak Berganda Duncan pada taraf $5 \%$. 
Tabel 3. Pengaruh Ketinggian Tempat Penanaman terhadap Jumlah Daun dan Bobot Kering Daun Pada 120 HST

\begin{tabular}{ccc}
\hline Lokasi Penanaman & Jumlah Daun (helai) & Bobot Kering Daun (gram) \\
\hline $200 \mathrm{~m} \mathrm{dpl}$ (Karanganyar) & $592.60 \mathrm{~b}$ & $274.35 \mathrm{~b}$ \\
$450 \mathrm{~m} \mathrm{dpl}$ (Karangpandan) & $441.56 \mathrm{a}$ & $162.15 \mathrm{a}$ \\
$1.200 \mathrm{~m} \mathrm{dpl}$ (Kalisoro) & $425.50 \mathrm{a}$ & $125.80 \mathrm{a}$ \\
\hline
\end{tabular}

Keterangan: Nilai rata-rata yang diikuti huruf yang sama pada kolom yang sama menunjukkan tidak berbeda nyata menurut Uji Jarak Berganda Duncan pada taraf $5 \%$.

Tabel 4. Pengaruh Ketinggian Tempat Penanaman terhadap Kadar Sari Larut Air. Kadar Sari Larut Ethanol dan Kadar Flavonoid Daun Duduk 120 HST

\begin{tabular}{cccc}
\hline \multirow{2}{*}{ Lokasi Penanaman } & \multicolumn{2}{c}{ Kadar Sari Larut Dalam } & \multirow{2}{*}{ Kadar Flavonoid (\%) } \\
\cline { 2 - 3 } & Air (\%) & Etanol (\%) & \\
\hline 200 m dpl (Karanganyar) & $19.23 \mathrm{~b}$ & $15.94 \mathrm{~b}$ & $0.212 \mathrm{~b}$ \\
450 m dpl (Karangpandan) & $19.73 \mathrm{~b}$ & $18.28 \mathrm{c}$ & $0.249 \mathrm{~b}$ \\
$1.200 \mathrm{~m} \mathrm{dpl}$ (Kalisoro) & $17.83 \mathrm{a}$ & $12.91 \mathrm{a}$ & $0.184 \mathrm{a}$ \\
\hline
\end{tabular}

Keterangan: Nilai rata-rata yang diikuti huruf yang sama pada kolom yang sama menunjukkan tidak berbeda nyata menurut Uji Jarak Berganda Duncan pada taraf $5 \%$.

Ketinggian tempat mempengaruhi kondisi iklim seperti suhu dan intensitas cahaya matahari. Suhu pada ketinggian 0 - $200 \mathrm{~m} \mathrm{dpl} \mathrm{mencapai} 29.45^{\circ} \mathrm{C}$, ketinggian $201-400 \mathrm{~m}$ dpl sekitar $28,07^{\circ} \mathrm{C}$, ketinggian $401-600 \mathrm{~m}$ dpl sekitar $25.61^{\circ} \mathrm{C}$, dan ketinggian $601-800 \mathrm{~m}$ dpl sekitar $24.74^{\circ} \mathrm{C}$. Perubahan suhu harian tiap $100 \mathrm{~m}$ dpl turun antara $0,5-1^{\circ} \mathrm{C}$ (Syarkawi et al. 2015).

Suhu yang lebih tinggi pada daun duduk yang ditanam di ketinggian $200 \mathrm{~m}$ dpl menyebabkan aktivitas metabolisme tanaman meningkat yang akan mendukung pertumbuhan daun sehingga jumlah dan bobot daun meningkat. Secara fisiologis, suhu dapat mempengaruhi pertumbuhan tanaman, fotosintesis, pembukaan stomata, dan respirasi. Selain itu, suhu merupakan salah satu penghambat dalam proses fisiologi untuk sistem produksi tanaman ketika suhu tanaman berada diluar suhu optimal terendah maupun tertinggi (Falah 2006).

Setiap tanaman memerlukan suhu optimum, suhu terlalu tinggi atau rendah menghambat pertumbuhan tanaman bahkan mengakibatkan tanaman mati. Sedangkan cahaya merupakan sumber tenaga untuk berlangsungnya metabolisme (Harwati 2008). Tingginya intensitas cahaya matahari pada ketinggian $200 \mathrm{~m}$ dpl akan meningkatkan fotosintesis dan respirasi dalam tanaman, sehingga translokasi hasil fotosisntesis ke seluruh jaringan tanaman lebih cepat dan mengakibatkan pertumbuhan jumlah cabang dan daun menjadi lebih banyak (Widiastuti et al. 2004).

\section{Kadar Sari Larut Air, Larut Etanol dan Kadar Flavonoid}

Penetapan kadar sari merupakan metode untuk mengetahui jumlah kandungan senyawa dalam simplisia yang dapat tersari dalam pelarut tertentu. Kadar sari yang larut dalam air lebih tinggi dibandingkan dengan kadar sari yang larut etanol (Tabel 4.). Senyawa metabolit sekunder yang terkandung dalam simplisia daun duduk seperti flavonoid lebih banyak bersifat polar sehingga banyak tersari ke dalam pelarut air. Flavonoid adalah golongan fenol alam yang luas dalam tumbuhan yang merupakan suatu senyawa polar karena mempunyai sejumlah gugus hidroksil atau gugus gula. Gula yang terikat pada flavonoid cenderung menyebabkan flavonoid lebih mudah larut dalam air (Harborne 1987, Markham 1988).

Penanaman di ketinggian $200 \mathrm{~m}$ dan $450 \mathrm{~m}$ dpl menghasilkan kadar flavonoid lebih tinggi dibandingkan daun duduk yang ditanam di ketinggian $1.200 \mathrm{~m} \mathrm{dpl}$ (Tabel 4.), diduga bahwa pada ketinggian tersebut merupakan kondisi lingkungan sesuai dalam pembentukan flavonoid pada tanaman daun duduk. Respon pembentukan flavonoid pada setiap tanaman terhadap ketinggian tempat budidaya tidak sama. Hasil penelitian Nikolova \& Ivancheva (2005) menunjukkan 
bahwa kadar flavonoid Artemisia vulgaris yang ditanam di ketinggian 700 - $2290 \mathrm{~m}$ dpl tidak berbeda nyata. Penelitian Bernal et al. (2013) melaporkan terjadi penurunan kandungan flavonoid pada daun Buxus sempervirens seiring meningkatnya ketinggian tempat penanaman. Kandungan flavonoid Fallopia japonica dan Larix kaempferi meningkat dengan meningkatnya ketinggian tempat tumbuh (Murai et al. 2015). Ghulamahdi et al. (2008) menyatakan bahwa senyawasenyawa golongan flavonoid dapat mengalami peningkatan karena pengaruh cahaya. Cahaya dalam proses fotosintesis akan menghasilkan glukosa-6-fospat sebagai prekursor pembentukan asetil Co-A yang selanjutnya menghasilkan senyawa flavonoid.

\section{SIMPULAN}

Ketinggian tempat budidaya dapat mempengaruhi pertumbuhan, produksi dan kualitas hasil tanaman daun duduk. Penanaman di ketinggian $450 \mathrm{~m}$ dpl menghasilkan kadar sari dan kadar flavonoid yang lebih tinggi, sedangkan produksi daun lebih tinggi dihasilkan pada penanaman di ketinggian $200 \mathrm{~m}$ dpl. Penanaman di ketinggian $1200 \mathrm{~m}$ dpl hanya meningkatkan pertumbuhan tinggi tanaman.

\section{UCAPAN TERIMAKASIH}

Penulis menyampaikan ucapan terima kasih pada Kepala Balai Besar Penelitian dan Pengembangan Tanaman Obat dan Obat Tradisional yang telah menyediakan fasilitas, serta semua rekan-rekan di Laboratorium Galenika, Laboratorium Instrumentasi dan para pihak yang telah membatu penelitian ini.

\section{DAFTAR PUSTAKA}

Bernal M, Llorens L, JulkunenTR, Badosa J, Verdaguer D. 2013. Altitudinal and seasonal changes of phenolic compounds in Buxus sempervirens leaves and cuticles. Plant Physiology and Biochemistry. 70: 471-82.

Beusekom V, González AE, Rivera, MM. 2015. Shortterm precipitation and temperature trends along an elevation gradient in Northeastern Puerto Rico. Earth Interactions. 19(3), 1-33.

Budiastuti MS. 2010. Ekologi umum; teori dasar pengelolaan lingkungan. Solo (ID): UNS Press.

Buntoro BH, Rogomulyo R, Trisnowati S. 2014. Pengaruh takaran pupuk kandang dan intensitas cahaya terhadap pertumbuhan dan hasil temu putih (Curcuma zedoaria L.). Vegetalika. 3(4): 29-39.
Dechairani S, Onggo TM, Sutari W. 2014. Pengaruh naungan net dan interval panen terhadap pertumbuhan tanaman hasil dan kualitas hasil buncis CV. Kenya di Jatinangor. Jurnal Kultivasi. 13(1): 33-44.

Falah MAF. 2006. Perspektif pertanian dalam lingkungan yang terkontrol. Inovasi. 6(18) 81-86

Flowrenzhy D. Harijati N. 2017. Pertumbuhan dan produktivitas tanaman cabai katokkon (Capsicum chinense Jacq.) di ketinggian 600 meter dan 1.200 meter di atas permukaan laut. Jurnal Biotropika. 5 (2): 44-53.

Ghulamahdi M, Sandra A, Nirwan A. 2008. Peningkatan laju pertumbuhan dan kandungan flavonoid klon daun dewa (Gynura pseudochina (L.)DC.) melalui periode pencahayaan. Buletin Agronomi. 48(36): 40-48.

Hakim NA. 2013. Perbedaan kualitas dan pertumbuhan benih edamame varietas ryoko yang diproduksi di ketinggian tempat yang berbeda di Lampung. Jurnal Penelitian Pertanian Terapan. 13 (1): 8-12.

Harborne JB. 1987. Metoda fitokimia: Penuntun cara modern menganalisis tumbuhan. Bandung: ITB.

Harwati CT. 2008. Pengaruh suhu dan panjang penyinaran terhadap umbi kentang (Solanum tuberosum, SSP). Jurnal Inovasi Pertanian. 7(1):11 18

Haryanto S. 2009. Ensiklopedi tanaman obat Indonesia. Jakarta (ID): Pall Mall.

Markham K. 1988. Cara mengidentifikasi flavanoid. Bandung (ID): ITB.

Murai Y, Setoguchi H, Kitajima J, Iwashina T. 2015. Altitudinal variation of flavonoid content in the leaves of Fallopia japonica and the needles of Larix kaempferi on Mt. Fuji. Natural Product Communications. 10(3): 407-411.

Nikolova MT, Ivancheva SV. 2005. Quantitative flavonoid variations of Artemisia vulgaris L. and Veronica chamaedrys L. in relation to altitude and polluted environment. Acta Biologica Szegediensis. 49(3-4): 29-32.

Nurnasari N dan Djumali. 2010. Pengaruh kondisi ketinggian tempat terhadap produksi dan mutu tembakau Temanggung. Buletin Tanaman Tembakau, Serat \& Minyak Industri. 2(2):45-59.

Pantilu LI, Mantin FR, Pandiangan D. 2012. Respons morfologi dan anatomi kecambah kacang kedelai (Glycine max (L.) Merill) terhadap intensitas cahaya yang berbeda. Jurnal Bioslogos. 2(2): 79-87. 
Sa'roni, Sediarso, Azizah YN. 2006. Efek diuretik Desmodium triquetrum (L.) DC. daun duduk pada hewan coba. Media Litbang Kesehatan. 16(3): 1923.

Supriadi H, Randriani E. Towaha J. 2015. Korelasi antara ketinggian tempat, sifat kimia tanah, dan mutu fisik biji kopi arabika di dataran tinggi Garut. Jurnal Tanman Industri dan Penyegar. 3(1): 45-52

Susilo S, Hargono D, Nurhayati S. 1989. Vademekum bahan obat alam. Jakarta (ID): Departemen Kesehatan.

Syamsuhidayat SS, Hutapea R. 1991. Inventaris tanaman obat Indonesia. Jakarta (ID): Badan Penelitian dan Pengembangan Kesehatan.

Syarkawi, Husni, Sayuthi M. 2015. Pengaruh Tinggi Tempat Terhadap Tingkat Serangan Hama Penggerek Buah Kakao (Conopomorpha cramerella Snellen) di Kabupaten Pidie. Jurnal Floratek. 10(2): 52-60.

Towaha J, Aunillah A, Purwanto EH, Supriadi H. 2014. Pengaruh Elevasi Dan Pengolahan Terhadap Kandungan Kimia Dan Citarasa Kopi Robusta
Lampung. Jurnal Tanaman Industri dan Penyegar. 1(1): 57-62.

Vedpal SP, Dhanabal P, Dhamodaran MV, Chaitnya NL, Duraiswamy B, Jayaram U, Neha S. 2016. Ethnopharmacological and phytochemical profile of three potent Desmodium species: Desmodium gangeticum (L.) DC, Desmodium triflorum Linn and Desmodium triquetrum Linn. Journal of Chemical and Pharmaceutical Research. 8(7): 91-97.

Widiastuti L, Tohari, Sulistyaningsih E. 2004. Pengaruh intensitas cahaya dan kadar daminosida terhadap iklim mikro dan pertumbuhan tanaman krisan dalam pot. Jurnal Ilmu Pertanian. 11(2): 35-42.

Zhang $\mathrm{M}$, Zhao $\mathrm{C}$, Liang $\mathrm{X}$, Ying $\mathrm{Y}$, Han $\mathrm{B}$, Yang $\mathrm{B}$, Jiang $\mathrm{C}$. 2016. Fingerprint analysis of Desmodium triquetrum L. based on ultra performance liquid chromatography with photodiode array detector combined with chemometrics methods. Journal of Chromatographic Science. 54(5): 706-712.

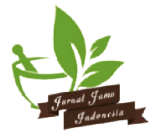

